\title{
Proximal muscle strength as a predictor of vitamin D insufficiency in elderly
}

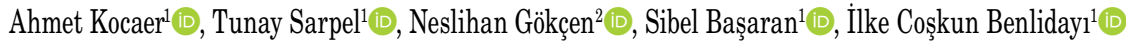 \\ ${ }^{1}$ Department of Physical Medicine and Rehabilitation, Çukurova University Faculty of Medicine, Adana, Turkey \\ ${ }^{2}$ Department of Physical Medicine and Rehabilitation, Division of Rheumatology, Çukurova University Faculty of Medicine, Adana, Turkey
}

Received: September 24, 2019 Accepted: December 26, 2019 Published online: March 04, 2021

\begin{abstract}
Objectives: This study aims to evaluate the association of serum vitamin D level with proximal muscle strength, tone, elasticity, and stiffness in elderly.

Patients and methods: Between September 2017 and January 2018, a total of 109 participants (21 males, 88 females; mean age: $71.2 \pm 4.6$ years; range, 65 to 85 years) were included in the study. The proximal muscle strength was evaluated by MicroFET $^{\oplus} 3$ device. The muscle tone, elasticity, and stiffness were measured using the MyotonPRO ${ }^{\circ}$ digital palpation device. Serum 25-hydroxyvitamin D [25(OH)D] level was tested by high-performance liquid chromatography. A receiver operating characteristic (ROC) curve was performed to evaluate the potential role of MicroFET ${ }^{\oplus} 3$-measured proximal muscle strength in the quantification of vitamin D status.

Results: Vitamin D sufficient participants had a higher proximal muscle strength $(\mathrm{p}<0.001)$. Quadriceps and hamstring elasticity at the non-dominant site were significantly higher in vitamin D sufficient group $(\mathrm{p}<0.05)$. The ROC analysis indicated that the deltoid muscle strength had the potential of determining vitamin D insufficiency with moderate accuracy (area under the curve $=0.744 ; 95 \%$ confidence interval: $0.643-0.845 ; \mathrm{p}<0.001)$.

Conclusion: Proximal muscle strength, elasticity, and physical performance are associated with vitamin D status. Proximal muscle strength measured by a hand-held dynamometer can be used as a predictor of hypovitaminosis D in elderly.

Keywords: Geriatrics, gerontology, muscle strength, muscle tension, muscle tone, vitamin D.
\end{abstract}

Vitamin $\mathrm{D}$ is an essential molecule for human beings. Vitamin D, either as ergocalciferol (vitamin D2) or cholecalciferol (vitamin D3), can regulate cell metabolism and physiology by means of vitamin D receptors (VDRs). ${ }^{[1,2]}$ Since VDRs are vastly expressed in musculoskeletal system tissues, vitamin $\mathrm{D}$ is highly involved in the muscle and bone metabolism. ${ }^{[3]}$

Vitamin D deficiency is regarded as an important public health issue. Decreased vitamin D level contributes to several comorbidities including malignancy, coronary heart disease, neurocognitive disorders, autoimmune-autoinflammatory diseases, and musculoskeletal disorders. ${ }^{[4,5]}$ The detrimental effects of vitamin D deficiency are more prominent in elderly. The most widely accepted theory about the sensitivity of elderly is that the expression of the VDRs declines with age. ${ }^{[6]}$ Furthermore, increasing age is related to decreased exposure to sunlight, major organ pathologies/failures, and inadequate oral intake of vitamin $D .{ }^{[5]}$ Thus, the prevalence of hypovitaminosis $\mathrm{D}$ can reach up to 90 to $100 \%$ of elderly population. ${ }^{[3,5]}$

A lack of vitamin D may lead to impaired muscle functions partly related to its impact on the biological properties of the muscle tissue. ${ }^{[3,7]}$ Prolonged

Corresponding author: İlke Coşkun Benlidayı, MD. Çukurova Üniversitesi Tıp Fakültesi, Fiziksel Tıp ve Rehabilitasyon Anabilim Dal, 01330 Sarıçam, Adana, Türkiye. e-mail: icbenlidayi@hotmail.com 
vitamin D deficiency or insufficiency may cause type 2 fiber atrophy, fatty infiltration, fibrosis, and increased glycogen granules in elderly. ${ }^{[6,8]}$ In the light these data, we, in the present study, aimed to evaluate the relation of vitamin D level with the strength, tone, elasticity, and stiffness of proximal muscles.

\section{PATIENTS AND METHODS}

This cross-sectional study was conducted at the Department of Physical Medicine and Rehabilitation, Faculty of Medicine, Çukurova University between September 2017 and January 2018. A total of 200 individuals aged $\geq 65$ years were assessed for eligibility. Exclusion criteria were as follows: (i) major organ failure, (ii) malignancy, (iii) malabsorptive conditions, iv) neurological disability, and $v$ ) history of endocrinological and/or gastroenterological surgery. Finally, a total of 109 participants ( 21 males, 88 females; mean age $71.2 \pm 4.6$ years; range, 65 to 85 years) were included in the study. A written informed consent was obtained from each participant. The study protocol was approved by the Ethics Committee of Çukurova University Faculty of Medicine (Date of approval: 8-September-2017, Approval number: 68/3). The study was conducted in accordance with the principles of the Declaration of Helsinki.

Demographic characteristics of all participants variables were recorded. Serum 25-hydroxyvitamin [25(OH)D] level was measured using high-performance liquid chromatography (HPLC). The serum samples were obtained in the morning after overnight fasting. In accordance with the guidelines of the Endocrine Society, the level of $25(\mathrm{OH}) \mathrm{D}$ was classified as sufficient $(\geq 30 \mathrm{ng} / \mathrm{mL}$ ), insufficient $(21-29 \mathrm{ng} / \mathrm{mL})$, and deficient $(<20 \mathrm{ng} / \mathrm{mL}) \cdot{ }^{[9]}$

The proximal muscle strength was evaluated by the MicroFET $^{\circledast} 3$ hand-held dynamometer (Hoggan Health Industries Inc., UT, USA). All measurements were done by a single physician and in the sitting position. For deltoid muscle, upper extremity was positioned in $90^{\circ}$ of shoulder abduction and internal rotation. The dynamometer was placed on the distal humerus nearby the lateral epicondyle. The strength of biceps muscle was tested, while the arm was at side and the forearm was at $90^{\circ}$ of flexion. The dynamometer was located on the volar side of the distal forearm close to the wrist. For triceps muscle, the elbow and the forearm were positioned at full extension in the coronal plane. The dynamometer was cited on the dorsal side of the distal forearm. The quadriceps strength was evaluated, while the knee was at full extension and the dynamometer was placed on the anterior aspect of the distal tibia. For hamstring muscle, the knee positioned at $90^{\circ}$ flexion, and the dynamometer was put on the posterior side of the distal tibia. Maximal voluntary isometric muscle contraction from elbow flexion and extension, knee flexion and extension, and shoulder abduction were measured three times. All measurements were based on the break technique. Accordingly, the physician attempted to overpower the efforts of the subject, while maximal voluntary isometric muscle contraction. The value where the examiner could break the participant's strength was regarded as the isometric muscle strength. The average strength of three consecutive measurements was calculated for each muscle and peak force was given in pounds. ${ }^{[10]}$

Mechanical properties (tone, elasticity, and stiffness) of the proximal muscles were evaluated using the MyotonPRO ${ }^{\circledR}$ (Myoton AS, Tallinn, Estonia) digital palpation device. The measurements were performed, while the participants were lying down in a relaxing position following a resting period of $10 \mathrm{~min}$. The MyotonPRO ${ }^{\infty}$ device was set to the multi-scan mode and to a pre-pressure of 0.18 Newtons (N). Deltoid, biceps, and quadriceps muscles were evaluated in the supine position. On the other hand, triceps and hamstring muscle measurements were performed in the prone position. The Myoton $\mathrm{PRO}^{\circ}$ was positioned perpendicular to the skin over the most bulky part of the muscle. A mechanical impulse at a force of $0.40 \mathrm{~N}$ was applied to the muscle for 15 microsec. The damped oscillations were recorded by an accelerometer. Resulting numerical values were calculated to depict the viscoelastic and biomechanical properties of the muscle. The average of two consecutive measurements was recorded for each tone, elasticity, and stiffness. ${ }^{[1,12]}$ Muscle tone is described by the frequency $(\mathrm{Hz})$ of the oscillations. Muscle elasticity is characterized by the logarithmic reduction of the oscillations. Muscle stiffness $(\mathrm{N} / \mathrm{m})$ represents the resistance of the muscle during contraction. ${ }^{[13]}$

Physical performance was evaluated by the Timed Up and Go (TUG) test. The participants were instructed to stand up from the armless chair without holding anywhere, come back to the chair after walking three meters with the normal pace, and sit down to the chair. All participants were allowed to wear comfortable shoes and not to use any mobility aids during the test. Walking duration was measured by a chronometer and recorded as sec. $^{[14,15]}$ 


\section{Statistical analysis}

Statistical analysis was performed by using the IBM SPSS version 20.0 (IBM Corp., Armonk, NY, USA). Descriptive data were expressed in mean \pm standard deviation (SD), median (min-max) or number and frequency. Data distribution was tested using the Shapiro-Wilk test. Comparative analysis was performed using the Mann-Whitney $U$ test and Kruskal Wallis test. Correlation of continuous variables was analyzed by the Spearman's rank test. Further post-hoc analysis was performed for two-group comparisons. A receiver operating characteristic (ROC) curve was used to evaluate the accuracy of proximal muscle strength in determining of vitamin D insufficiency. A $p$ value of $<0.05$ was considered statistically significant.

\section{RESULTS}

Of a total of 200 elderly individuals, 91 were excluded from the study due to chronic kidney disease $(n=43)$, history of gastroenterological disorders $(n=37)$, neurological disability $(\mathrm{n}=25)$, and ongoing malignancy $(n=9)$. Demographic characteristics of all participants $(n=109)$ included in the study are shown in Table 1.

The median 25(OH)D level was $21.7 \mathrm{ng} / \mathrm{mL}$. Of the participants, $30.3 \%$ and $42.2 \%$ had vitamin D insufficiency and deficiency, respectively. When the sample was categorized into three as vitamin $\mathrm{D}$ deficient, vitamin $\mathrm{D}$ insufficient, and

\begin{tabular}{|c|c|c|c|c|}
\hline \multicolumn{5}{|c|}{$\begin{array}{c}\text { TABLE } 1 \\
\text { Demographic characteristics of study population }(n=109)\end{array}$} \\
\hline & $\mathrm{n}$ & $\%$ & Median & Min-Max \\
\hline Age (years) & & & 71 & $65-85$ \\
\hline \multicolumn{5}{|l|}{ Sex } \\
\hline Male & 21 & 19.3 & & \\
\hline Female & 88 & 80.7 & & \\
\hline Height $(\mathrm{cm})$ & & & 158 & $142-180$ \\
\hline Weight $(\mathrm{kg})$ & & & 72 & $40-102$ \\
\hline Body mass index $\left(\mathrm{kg} / \mathrm{m}^{2}\right)$ & & & 27.9 & $17.5-41.9$ \\
\hline
\end{tabular}

vitamin D sufficient groups, the body mass index was significantly higher in vitamin $\mathrm{D}$ deficient group ( $p=0.005)$. On the other hand, there was no significant difference among the groups in terms of age, sex, height, employment status, smoking, and alcohol consumption.

The proximal muscle strength showed a statistically significant difference among vitamin $D$ groups $(\mathrm{p}<0.001)$. Vitamin D deficient group had the lowest values for each tested muscle strength (Table 2). In terms of physical performance, the median duration of TUG test was $12.6 \mathrm{sec}$ and $12.1 \mathrm{sec}$ in vitamin $\mathrm{D}$ deficient and insufficient groups, respectively $(p=0.043)$. On the other hand, proximal muscle biomechanical properties (tone, elasticity, and stiffness) were not different among the groups, except for the elasticity of

\begin{tabular}{|c|c|c|c|c|c|c|c|}
\hline \multicolumn{8}{|c|}{$\begin{array}{c}\text { TABLE } 2 \\
\text { Comparison of muscle strength among vitamin D groups }\end{array}$} \\
\hline & \multicolumn{2}{|c|}{ Deficient } & \multicolumn{2}{|c|}{ Insufficient } & \multicolumn{2}{|c|}{ Sufficient } & \multirow[b]{2}{*}{$p$} \\
\hline & Median & Q1-Q3 & Median & Q1-Q3 & Median & Q1-Q3 & \\
\hline \multicolumn{8}{|l|}{ Deltoid } \\
\hline Dominant & 6.1 & $5.4-6.5$ & 6.8 & $5.8-7.3$ & 7.4 & $6.8-7.6$ & $<0.001$ \\
\hline Non dominant & 5.5 & $5.1-6.2$ & 6.1 & $5.4-6.9$ & 6.9 & $6.4-7.2$ & $<0.001$ \\
\hline \multicolumn{8}{|l|}{ Biceps } \\
\hline Dominant & 6.4 & $5.8-6.8$ & 6.9 & $6.1-7.5$ & 7.2 & $6.2-7.2$ & $<0.001$ \\
\hline Non dominant & 5.9 & $5.3-6.3$ & 6.3 & $5.8-6.9$ & 6.9 & $5.0-7.7$ & $<0.001$ \\
\hline \multicolumn{8}{|l|}{ Triceps } \\
\hline Dominant & 5.6 & 4.9-5.9 & 6.4 & $5.8-6.9$ & 6.4 & $6.0-6.8$ & $<0.001$ \\
\hline Non dominant & 5.3 & $4.0-7.0$ & 5.9 & $5.3-6.5$ & 6.1 & $5.8-6.2$ & 0.001 \\
\hline \multicolumn{8}{|l|}{ Quadriceps } \\
\hline Dominant & 6.5 & $5.8-7.1$ & 7.0 & $6.5-7.8$ & 7.2 & $7.0-7.4$ & $<0.001$ \\
\hline Non dominant & 6.0 & $5.3-6.6$ & 6.5 & $6.0-7.2$ & 6.8 & $6.4-7.3$ & 0.001 \\
\hline \multicolumn{8}{|l|}{ Hamstring } \\
\hline Dominant & 6.2 & $5.8-6.5$ & 6.8 & $6.1-7.3$ & 7.1 & $6.5-7.4$ & 0.001 \\
\hline Non dominant & 5.8 & $5.3-6.2$ & 6.4 & $5.4-6.9$ & 6.6 & $6.1-7.0$ & 0.001 \\
\hline
\end{tabular}


quadriceps and hamstring muscle (only at the non-dominant site), which was significantly higher in vitamin $\mathrm{D}$ sufficient participants $(\mathrm{p}<0.05$ for quadriceps and hamstring muscles, post hoc $=0.043$ ) (Table 3 ).
The ROC analysis was performed to evaluate the ability of proximal muscle strength to predict vitamin $\mathrm{D}$ status in elderly. Accordingly, the area under the curve (AUC) of deltoid muscle strength for determining

\begin{tabular}{|c|c|c|c|c|c|c|c|c|c|}
\hline \multicolumn{10}{|c|}{$\begin{array}{c}\text { TABLE } 3 \\
\text { Comparison of biomechanical properties among vitamin D groups }\end{array}$} \\
\hline & \multicolumn{2}{|c|}{ Deficient } & \multicolumn{2}{|c|}{ Insufficient } & \multicolumn{2}{|c|}{ Sufficient } & \multicolumn{2}{|c|}{ Total } & \multirow[b]{2}{*}{$p$} \\
\hline & Median & Q1-Q3 & Median & Q1-Q3 & Median & Q1-Q3 & Median & Q1-Q3 & \\
\hline \multicolumn{10}{|l|}{ Deltoid } \\
\hline Dominant & 15.0 & $13.9-17.4$ & 16.5 & $14.1-18.0$ & 15.5 & $14.0-17.6$ & 15.5 & $14.0-17.6$ & 0.465 \\
\hline Non dominant & 15.1 & $12.8-16.5$ & 15.2 & $13.4-16.7$ & 15.1 & $13.4-16.5$ & 15.1 & $13.4-16.5$ & 0.760 \\
\hline \multicolumn{10}{|l|}{ Elasticity } \\
\hline Dominant & 1.20 & $1.02-1.34$ & 1.22 & $1.02-1.39$ & 1.20 & $1.02-1.34$ & 1.20 & $1.02-1.34$ & 0.663 \\
\hline \multicolumn{10}{|l|}{ Stiffness } \\
\hline Dominant & 242.0 & $190.5-293.5$ & 245.0 & $200.5-302.0$ & 246.0 & $197.5-299.5$ & 246.0 & $197.5-299.5$ & 0.799 \\
\hline Non dominant & 227.0 & $198.5-301.8$ & 256.0 & $191.0-277.5$ & 238.0 & $198.0-284.5$ & 238.0 & $198.0-284.5$ & 0.976 \\
\hline \multicolumn{10}{|l|}{ Biceps } \\
\hline Dominant & 14.0 & $13.0-14.9$ & 13.4 & $12.6-14.2$ & 13.7 & $12.6-14.8$ & 13.7 & $12.6-14.8$ & 0.209 \\
\hline Non dominant & 13.3 & $12.3-14.0$ & 12.4 & $12.0-13.5$ & 13.0 & $12.1-14.0$ & 13.0 & $12.1-14.0$ & 0.180 \\
\hline \multicolumn{10}{|l|}{ Elasticity } \\
\hline Dominant & 1.40 & $1.22-1.57$ & 1.39 & $1.15-1.60$ & 1.40 & $1.19-1.58$ & 1.40 & $1.19-1.58$ & 0.903 \\
\hline Non dominant & 1.36 & $1.25-1.54$ & 1.38 & $1.26-1.55$ & 1.35 & $1.24-1.53$ & 1.35 & $1.24-1.53$ & 0.398 \\
\hline \multicolumn{10}{|l|}{ Stiffness } \\
\hline Dominant & 237.5 & $211.8-259.5$ & 221.0 & $198.0-241.0$ & 232.0 & $208.5-252.0$ & 232.0 & $208.5-252.0$ & 0.111 \\
\hline Non dominant & 231.5 & $207.5-248.0$ & 222.0 & $209.5-242.5$ & 224.0 & $207.0-244.5$ & 224.0 & $207.0-244.5$ & 0.441 \\
\hline \multicolumn{10}{|l|}{ Triceps } \\
\hline \multicolumn{10}{|l|}{ Tone } \\
\hline Dominant & 12.6 & $11.0-13.6$ & 13.2 & $11.5-14.6$ & 12.8 & $11.2-14.2$ & 12.8 & $11.2-14.2$ & 0.269 \\
\hline Non dominant & 12.4 & $11.0-13.7$ & 12.5 & $11.0-14.2$ & 12.3 & $11.0-14.0$ & 12.3 & $11.0-14.0$ & 0.320 \\
\hline \multicolumn{10}{|l|}{ Elasticity } \\
\hline Dominant & 1.96 & $1.71-2.40$ & 1.94 & $1.38-2.25$ & 1.94 & $1.66-2.32$ & 1.94 & $1.66-2.32$ & 0.660 \\
\hline Non dominant & 1.74 & $1.55-2.02$ & 1.74 & $1.49-1.98$ & 1.74 & $1.55-2.03$ & 1.74 & $1.55-2.03$ & 0.784 \\
\hline \multicolumn{10}{|l|}{ Stiffness } \\
\hline Dominant & 241.5 & $214.0-288.8$ & 249.0 & $205.5-272.0$ & 248.0 & $215.5-284.0$ & 248.0 & $215.5-284.0$ & 0.621 \\
\hline Non dominant & 251.5 & $224.8-275.8$ & 244.0 & $216.0-285.5$ & 253.0 & $221.5-275.0$ & 253.0 & $221.5-275.0$ & 0.824 \\
\hline \multicolumn{10}{|l|}{ Quadriceps } \\
\hline Tone & & & & & & & & & \\
\hline Dominant & 12.9 & $12.4-14.4$ & 13.3 & $11.9-15.2$ & 13.0 & $11.9-14.4$ & 13.0 & $11.9-14.4$ & 0.912 \\
\hline Non dominant & 13.1 & $11.9-14.1$ & 13.0 & $11.9-14.2$ & 13.0 & $11.9-14.1$ & 13.0 & $11.9-14.1$ & 0.959 \\
\hline Elasticity & & & & & & & & & \\
\hline Dominant & 1.38 & $1.11-1.67$ & 1.55 & $1.21-1.82$ & 1.46 & $1.21-1.75$ & 1.46 & $1.21-1.75$ & 0.160 \\
\hline Non dominant & 1.30 & $1.10-1.54$ & 1.55 & $1.27-1.78$ & 1.43 & $1.24-1.71$ & 1.43 & $1.24-1.71$ & 0.021 \\
\hline Stiffness & & & & & & & & & \\
\hline Dominant & 224.5 & $196.5-247.8$ & 225.0 & $197.0-279.5$ & 225.0 & $196.0-256.5$ & 225.0 & $196.0-256.5$ & 0.697 \\
\hline Non dominant & 226.5 & $196.5-255.3$ & 228.0 & $209.0-254.5$ & 228.0 & $204.0-255.0$ & 228.0 & $204.0-255.0$ & 0.519 \\
\hline Hamstring & & & & & & & & & \\
\hline Tone & & & & & & & & & \\
\hline Dominant & 13.7 & $12.3-15.0$ & 12.9 & $11.9-15.3$ & 13.3 & $12.3-14.7$ & 13.3 & $12.3-14.7$ & 0.606 \\
\hline Non dominant & 12.5 & $11.4-14.0$ & 12.6 & $11.4-14.3$ & 12.5 & $11.4-13.4$ & 12.5 & $11.4-13.4$ & 0.836 \\
\hline Elasticity & & & & & & & & & \\
\hline Dominant & 1.47 & $1.30-1.73$ & 1.59 & $1.42-1.88$ & 1.51 & $1.40-1.85$ & 1.51 & $1.40-1.85$ & 0.131 \\
\hline Non dominant & 1.44 & $1.22-1.61$ & 1.55 & $1.30-1.79$ & 1.45 & $1.35-1.67$ & 1.45 & $1.35-1.67$ & 0.033 \\
\hline Stiffness & & & & & & & & & \\
\hline Dominant & 227.0 & $203.8-255.3$ & 238.0 & $209.0-258.0$ & 234.0 & $206.5-256.0$ & 234.0 & $206.5-256.0$ & 0.736 \\
\hline Non dominant & 220.5 & $187.5-241.5$ & 224.0 & $119.0-261.5$ & 223.0 & $194.0-247.5$ & 223.0 & $194.0-247.5$ & 0.508 \\
\hline
\end{tabular}




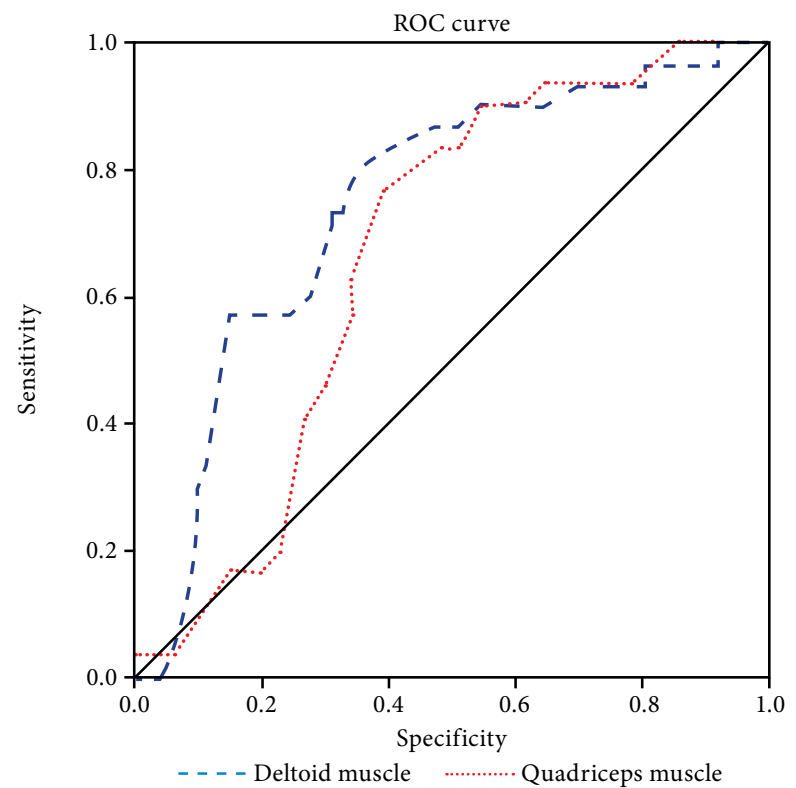

Figure 1. ROC curves of deltoid and quadriceps muscle strength in determining vitamin D insufficiency (AUC for deltoid $=0.744$; AUC for quadriceps $=0.667$ ).

ROC: Receiver operating characteristics; AUC: Area under the curve.

vitamin D insufficiency was $0.744 \quad(\mathrm{p}<0.001)$. The best cut-off value for deltoid muscle strength was calculated as $7.0 \mathrm{lb}$. Using this cut-off value, diagnostic sensitivity and specificity of the deltoid muscle strength were $68.4 \%$ and $73.3 \%$, respectively. On the other hand, the ROC curve of quadriceps muscle strength (cut-off value $=7.1 \mathrm{lb}$ ) showed lower accuracy in predicting vitamin D status (AUC=0.667; $\mathrm{p}=0.007$; sensitivity $=65.8 \%$; specificity $=63.3 \%$ ) (Figure 1$)$.

\section{DISCUSSION}

Vitamin D is a secosteroid hormone essential for calcium and phosphate metabolism. ${ }^{[16]}$ Vitamin D deficiency is a common condition affecting almost one billion individuals in the world. ${ }^{[17]}$ Over the past decade, there has been an extensive amount of research on this topic. ${ }^{[18-21]}$ The results from these studies have shown that vitamin D deficiency is more common in elderly, compared to younger adults. ${ }^{[20,21]}$ Consistent with the literature, the current study showed that $72.5 \%$ of elderly had vitamin D insufficiency [25(OH)D level $<30 \mathrm{ng} / \mathrm{mL}$ ]. Age-related decreases in dietary intake, exposure to sunlight, gastrointestinal absorption, and hydroxylation capacity are some of the underlying causes of vitamin D insufficiency/deficiency in elderly population. ${ }^{[22]}$

There are several detrimental effects of decreased vitamin D level on human metabolism. ${ }^{[23]}$ One of the most prominent health effects of vitamin D deficiency is seen in the musculoskeletal system. ${ }^{[24]}$ It has a strong negative impact on bone health. Rickets, osteomalacia, osteopenia, and osteoporosis are conditions associated with vitamin $\mathrm{D}$ deficiency. Vitamin $\mathrm{D}$ also affects muscle mass, muscle strength, and neuromuscular performance. ${ }^{[24,25]}$ It may also have an impact on the biomechanical properties of the muscle. With this hypothesis in mind, we evaluated the potential effect of vitamin D status proximal muscle biomechanical properties including tone, elasticity, and stiffness in our study. However, other than the elasticity component, there was no relationship between the muscle biomechanical properties and vitamin D status. Elasticity of quadriceps and hamstring muscle at the non-dominant extremity was significantly higher in vitamin D sufficient individuals. The literature search reveals no study evaluating the relationship between vitamin $\mathrm{D}$ status and muscle biomechanical properties using the MyotonPRO ${ }^{\circ}$ device. On the other hand, there is a limited number of data regarding the impact of age/sex on the biomechanical properties of muscles. Agyapong-Badu et al., ${ }^{[26]}$ in their study, evaluated tone, elasticity, and strength of the biceps and rectus femoris muscles. These three biomechanical parameters were compared between young adults (20-35 years of age) and elderly (65-82 years of age). Elderly participants revealed higher stiffness and lower elasticity in biceps and rectus femoris muscles than young adults. On the other hand, tone was higher in biceps muscle in elderly with no difference in rectus femoris muscle between the groups. The authors also showed no impact of sex on muscle elasticity in elderly group. However, the present study demonstrated that proximal muscle elasticity, tone, and stiffness were higher in men than those in women. Further studies are warranted to clarify the potential role of age, sex, and vitamin $\mathrm{D}$ status on the biomechanical properties of muscles in elderly.

The present study confirmed once again that hypovitaminosis $\mathrm{D}$ is an important determinant of muscle strength in elderly. The vitamin $\mathrm{D}$ deficient group had the lowest values for each tested muscle strength by MicroFET ${ }^{\oplus} 3$. With regard to the physical performance, participants with a $25(\mathrm{OH}) \mathrm{D}$ level of $<20 \mathrm{ng} / \mathrm{mL}$ revealed a longer median duration of TUG test than those with a vitamin $\mathrm{D}$ level of $>20 \mathrm{ng} / \mathrm{mL}$. Houston et al., ${ }^{[27]}$ in their cross-sectional study, evaluated physical performance among elderly by Short Physical Performance Battery and hand grip strengths using a hand dynamometer. Physical performance scores were significantly lower in the 
vitamin D deficient group, compared to participants with $25(\mathrm{OH}) \mathrm{D}$ level of $>10 \mathrm{ng} / \mathrm{mL}$. In terms of hand grip strength, there was a significant difference between vitamin D insufficient and sufficient groups. A multi-center, retrospective study compared muscle strength between postmenopausal women with optimal vitamin D level and those with a $25(\mathrm{OH}) \mathrm{D}$ level of $<30 \mathrm{ng} / \mathrm{mL} .^{[28]}$ The handgrip strength and lower extremity isokinetic knee extensor strength were significantly lower in participants with suboptimal vitamin $\mathrm{D}$ level. Additionally, muscle strength was found to be significantly correlated with $25(\mathrm{OH}) \mathrm{D}$ level. ${ }^{[28]}$

Given the close relationship between proximal muscle strength and vitamin D level in older adults, we further postulated that proximal muscle strength could be used to predict vitamin $\mathrm{D}$ deficiency in daily clinical practice. With this aim, further ROC analysis was carried out to determine whether muscles properties (strength, tone, elasticity and stiffness) had any diagnostic value in determining the vitamin $\mathrm{D}$ status of elderly individuals. Myotonometric measures including tone, elasticity, and stiffness were found to have no diagnostic role in estimating the vitamin $\mathrm{D}$ level. However, the proximal muscle strength measured by MicroFET $^{\oplus} 3$ hand-held dynamometer revealed a predictive value with moderate $(\mathrm{AUC}=0.744)$ and low $(A U C=0.667)$ diagnostic accuracies for deltoid and quadriceps muscles, respectively. It was found that a deltoid muscle strength of $7.0 \mathrm{lb}$ showed $68.4 \%$ sensitivity and $73.3 \%$ specificity in discriminating between sufficient $(>30 \mathrm{ng} / \mathrm{mL})$ and insufficient $(<30 \mathrm{ng} / \mathrm{mL})$ levels of vitamin $\mathrm{D}$. To the best of our knowledge, this is the first study to evaluate the muscle strength as a diagnostic tool in determining vitamin the status. There are many detrimental clinical consequences of vitamin D insufficiency/deficiency in elderly. One can consider screening the vitamin D level of every single individual and to tailor supplementation accordingly. However, given the high costs of serum $25(\mathrm{OH}) \mathrm{D}$ testing and lack of enough evidence, several authorities do not recommend routine screening in elderly. ${ }^{[29,30]}$ On the other hand, while supplementing the patient without a priori testing, it is important to avoid high levels of vitamin $\mathrm{D}$, since serum vitamin $\mathrm{D}$ level has a U-shaped relationship with several health conditions with its overdose, leading to an increased fall risk and fractures. ${ }^{[31,32]}$ Therefore, it would be of great value to anticipate hypovitaminosis D using a cheap and practical method in daily clinical practice. Accordingly, many researchers have attempted to find alternative ways to evaluate vitamin D level. Annweiler et al. ${ }^{[33,34]}$ developed a clinical diagnostic tool for the identification of older community-dwellers with hypovitaminosis D. However, none has evaluated the predictive role of proximal muscle strength so far.

In conclusion, there is a close relationship between the muscle strength and vitamin D status. Proximal muscle strength measurement results are valuable in terms of estimating vitamin D status in elderly. Given the moderate diagnostic accuracy of deltoid muscle test results, deltoid muscle strength measured by a hand-held dynamometer can be used as a predictor tool for hypovitaminosis D in elderly population.

\section{Declaration of conflicting interests}

The authors declared no conflicts of interest with respect to the authorship and/or publication of this article.

Funding

The authors received no financial support for the research and/or authorship of this article.

\section{REFERENCES}

1. Pludowski P, Holick MF, Grant WB, Konstantynowicz J, Mascarenhas MR, Haq A, et al. Vitamin D supplementation guidelines. J Steroid Biochem Mol Biol 2018;175:125-35.

2. Medrano M, Carrillo-Cruz E, Montero I, Perez-Simon JA. Vitamin D: Effect on Haematopoiesis and Immune System and Clinical Applications. Int J Mol Sci 2018;19. pii: E2663.

3. Duval G, Rolland Y, Schott AM, Blain H, Dargent-Molina $\mathrm{P}$, Walrand S, et al. Association of hypovitaminosis D with triceps brachii muscle fatigability among older women: Findings from the EPIDOS cohort. Maturitas 2018;111:47-52.

4. Caccamo D, Ricca S, Currò M, Ientile R. Health Risks of Hypovitaminosis D: A Review of New Molecular Insights. Int J Mol Sci 2018;19. pii: E892.

5. Suryanarayana P, Arlappa N, Sai Santhosh V, Balakrishna N, Lakshmi Rajkumar P, Prasad U, et al. Prevalence of vitamin $\mathrm{D}$ deficiency and its associated factors among the urban elderly population in Hyderabad metropolitan city, South India. Ann Hum Biol 2018;45:133-9.

6. Sanders KM, Scott D, Ebeling PR. Vitamin D deficiency and its role in muscle-bone interactions in the elderly. Curr Osteoporos Rep 2014;12:74-81.

7. Gunton JE, Girgis CM. Vitamin D and muscle. Bone Rep 2018;8:163-7.

8. Angeline ME, Ma R, Pascual-Garrido C, Voigt C, Deng $\mathrm{XH}$, Warren RF, et al. Effect of diet-induced vitamin D deficiency on rotator cuff healing in a rat model. Am J Sports Med 2014;42:27-34.

9. Holick MF. The vitamin D deficiency pandemic: Approaches for diagnosis, treatment and prevention. Rev Endocr Metab Disord 2017;18:153-65.

10. Kelln BM, McKeon PO, Gontkof LM, Hertel J. Hand-held dynamometry: reliability of lower extremity muscle testing in healthy, physically active,young adults. J Sport Rehabil 2008; 17:160-70. 
11. MyotonPro user guide. Available at: https://www.myoton. com [Accessed: July 6, 2019]

12. Aird L, Samuel D, Stokes M. Quadriceps muscle tone, elasticity and stiffness in older males: reliability and symmetry using the MyotonPRO. Arch Gerontol Geriatr 2012;55:e31-9.

13. Chuang LL, Wu CY, Lin KC. Reliability, validity, and responsiveness of myotonometric measurement of muscle tone, elasticity, and stiffness in patients with stroke. Arch Phys Med Rehabil 2012;93:532-40.

14. Ibrahim A, Singh DKA, Shahar S. 'Timed Up and Go' test: Age, gender and cognitive impairment stratified normative values of older adults. PLoS One 2017;12:e0185641.

15. Podsiadlo D, Richardson S. The timed "Up \& Go": a test of basic functional mobility for frail elderly persons. J Am Geriatr Soc 1991;39:142-8.

16. Holick MF. Vitamin D deficiency. N Engl J Med 2007;357:266-81.

17. Pérez-López FR. Vitamin D and its implications for musculoskeletal health in women: an update. Maturitas 2007;58:117-37.

18. Coskun Benlidayi I, Basaran S, Seydaoglu G, Guzel R. Vitamin D profile of patients with spinal cord injury and post-stroke hemiplegia: All in the same boat. J Back Musculoskelet Rehabil 2016;29:205-10.

19. Gokcen N, Coskun Benlidayi I, Kocaer A, Basaran S. Association between vitamin D level and total comorbidity status in geriatric patients. Turk J Geriatrics 2018;21:536-43.

20. Miettinen ME, Smart MC, Kinnunen L, KeinänenKiukaanniemi S, Moilanen L, Puolijoki H, et al. The effect of age and gender on the genetic regulation of serum 25-hydroxyvitamin D - the FIN-D2D populationbased study. J Steroid Biochem Mol Biol 2018;178:22933.

21. Zadshir A1, Tareen N, Pan D, Norris K, Martins D. The prevalence of hypovitaminosis D among US adults: data from the NHANES III. Ethn Dis 2005;15:S5-97-101.

22. Halfon M, Phan O, Teta D. Vitamin D: a review on its effects on muscle strength, the risk of fall, and frailty. Biomed Res Int 2015;2015:953241.

23. Coskun Benlidayi I. Is vitamin D a panacea? Rheumatol Int 2019. [Epub ahead of print]
24. Wintermeyer E, Ihle C, Ehnert S, Stöckle U, Ochs G, de Zwart $\mathrm{P}$, et al. Crucial role of vitamin D in the musculoskeletal system. Nutrients 2016;8. pii: E319.

25. Montenegro KR, Cruzat V, Carlessi R, Newsholme P. Mechanisms of vitamin D action in skeletal muscle. Nutr Res Rev 2019;32:192-204.

26. Agyapong-Badu S, Aird L, Bailey L, Mooney K, Mullix $\mathrm{J}$, Warner $\mathrm{M}$, et al. Interrater reliability of muscle tone, stiffness and elasticity measurements of rectus femoris and biceps brachii in healthy young and older males. Working Papers in the Health Sciences 2013;4 Summer:1-10.

27. Houston DK, Cesari M, Ferrucci L, Cherubini A, Maggio D, Bartali B, et al. Association between vitamin D status and physical performance: the InCHIANTI study. J Gerontol A Biol Sci Med Sci 2007;62:440-6.

28. Iolascon G, Mauro GL, Fiore P, Cisari C, Benedetti MG, Panella L, et al. Can vitamin D deficiency influence muscle performance in postmenopausal women? A multicenter retrospective study. Eur J Phys Rehabil Med 2018;54:676-82.

29. US Preventive Services Task Force. Final recommendation statement: Vitamin D deficiency: Screening. Avaliable from: www.uspreventiveservicestaskforce.org/Page/Document/ RecommendationStatementFinal/vitamin-d-deficiencyscreening. [Accessed: June 15, 2019].

30. Holick MF, Binkley NC, Bischoff-Ferrari HA, Gordon CM, Hanley DA, Heaney RP, et al. Evaluation, treatment, and prevention of vitamin D deficiency: an Endocrine Society clinical practice guideline. J Clin Endocrinol Metab 2011;96:1911-30.

31. Bischoff-Ferrari HA, Dawson-Hughes B, Orav EJ, Staehelin HB, Meyer OW, Theiler R, et al. Monthly highdose vitamin $d$ treatment for the prevention of functional decline: a randomized clinical trial. JAMA Intern Med 2016;176:175-83.

32. Gallagher JC. Vitamin D and falls - the dosage conundrum. Nat Rev Endocrinol 2016;12:680-4.

33. Annweiler C, Kabeshova A, Legeay M, Fantino B, Beauchet O. Derivation and validation of a clinical diagnostic tool for the identification of older community-dwellers with hypovitaminosis D. J Am Med Dir Assoc 2015;16:536.e8-19.

34. Annweiler C, Riou J, Alessandri A, Gicquel D, Henni S, Féart $\mathrm{C}$, et al. Clinical identification of geriatric patients with hypovitaminosis D: The 'Vitamin D status predictor for geriatrics' study. Nutrients 2017;9. pii: E658. 